\title{
Polymorphisms and plasma levels of IL-27: impact on genetic susceptibility and clinical outcome of bladder cancer
}

\author{
Bin Zhou ${ }^{1 \dagger}$, Peng Zhang ${ }^{2 \dagger}$, Tielong Tang ${ }^{3}$, Hong Liao ${ }^{4}$, Kui Zhang ${ }^{5}$, Yan Pu ${ }^{5}$, Peng Chen ${ }^{5}$, Yaping Song ${ }^{1}$ \\ and Lin Zhang ${ }^{\text {** }}$
}

\begin{abstract}
Background: Interleukin-27 (IL-27) has been recognized as a pleiotropic cytokine with both pro- and anti-inflammatory properties. Few studies have investigated polymorphisms and serum/plasma levels of IL-27 in diseases including cancers. This study has analyzed the associations of IL-27 gene polymorphisms, as well as plasma levels of IL-27, with susceptibility to bladder cancer and clinical outcome.
\end{abstract}

Methods: Three hundred and thirty-two patients (nonmuscle-invasive bladder cancer (NMIBC)/muscle-invasive bladder cancer (MIBC): 176/156) included in a 60-month follow-up program and 499 controls were enrolled. Two single nucleotide polymorphisms (SNPs), rs153109 and rs17855750, were genotyped by polymerase chain reaction (PCR) -restriction fragment length polymorphism (RFLP) method. Plasma concentration of IL-27 was determined by ELISA in 124 patients (NMIBC/MIBC: 50/74) and 151 controls.

Results: Significantly increased risk for bladder cancer was associated with AG/GG genotypes of rs153109 $(P=0.029)$. No GG genotype of rs 17855750 was observed in controls, while 4 patients were found to be GG homozygotes, suggesting GG genotype may be associated with bladder cancer risk $(P=0.006)$. For bladder cancer patients, SNP rs 17855750 was also associated with increased risk for MIBC. For MIBC patients, but not NMIBC, TG/GG genotypes of rs 17855750 turned out to be a protective factor for overall survival $(P=0.035)$. Significantly reduced plasma levels of IL-27 were observed in both NMIBC and MIBC patients compared with controls $(P<0.0001)$.

Conclusion: Our data suggest that polymorphisms and reduced plasma levels of IL-27 may predict the susceptibility to bladder cancer, and rs 17855750 may be a useful marker to distinguish patients with high risk of death.

Keywords: Bladder cancer, IL-27, Polymorphisms, Plasma levels, Susceptibility, Prognosis

\section{Background}

Bladder cancer is one of the most common cancers worldwide and the most frequent malignancy of the urinary tract [1]. In China, bladder cancer is the tenth most common cancer, accounting for 17,365 deaths in 2005 and mortality has steadily increased between 1991 and 2005 [2]. Transitional cell carcinoma of the urinary

\footnotetext{
* Correspondence: zhanglin@scu.edu.cn

${ }^{\dagger}$ Equal contributors

'Laboratory of Molecular Translational Medicine, West China Institute of Women and Children's Health, Key Laboratory of Obstetric \& Gynecologic and Pediatric Diseases and Birth Defects of Ministry of Education, West China Second University Hospital, Sichuan University, Chengdu, Sichuan, P R China Full list of author information is available at the end of the article
}

bladder represents more than $90 \%$ of all bladder cancers, approximately $80 \%$ of which are nonmuscleinvasive bladder cancer (NMIBC). The vast majority of cancer-specific deaths are due to muscle-invasive bladder cancer (MIBC), although only about $20 \%$ of bladder cancer patients are diagnosed with MIBC. Tobacco smoking and occupational or environmental exposure to chemical carcinogens are the most and wellestablished risk factors for bladder cancer. However, only a few of the exposed individuals develop bladder cancer in their lifetime, suggesting that genetic factor may also play a crucial role in the pathogenesis of bladder cancer [3]. 
Cancer is a hyperproliferative disorder involving sustaining proliferative signaling, evading growth suppressors, resisting cell death, enabling replicative immortality, inducing angiogenesis, activating invasion and metastasis, reprogramming of energy metabolism, and evading immune destruction [4, 5]. Clinical and epidemiologic studies have suggested that inflammation can play a direct role in cancer [6, 7]. Inflammation, which orchestrates the tumor microenvironment, is involved in tumor initiation, promotion, and progression [8-10]. In bladder carcinogenesis, findings from numerous studies have suggested that inflammation is likely to have an important role [11]. Creactive protein (CRP), which is an acute-phase reactant and a useful marker of systemic inflammation, has been shown to be a biomarker for bladder cancer [12-14].

Interleukin-27 (IL-27) is a heterodimeric cytokine composed of the Epstein-Barr virus-induced gene 3 (EBI3) and IL-27p28, which engages a receptor composed of gp130 and the IL-27R $\alpha$ that activates Janus kinase (JAK)-signal transducer and activator of transcription (STAT) and mitogen activated protein kinase (MAPK) signaling [15, 16]. IL-27, which is a member of the IL-12 family of cytokines and chiefly produced by antigen-presenting cells (APC) such as dendritic cell (DCs) and macrophages, was initially described as a proinflammatory cytokine that promoted T helper (Th)1 responses [17]. Subsequent studies have confirmed an anti-inflammatory role for IL-27 in Th1, Th2, and Th17 responses, and it has also been shown that IL-27 can induce $\mathrm{T}$ cells to produce the antiinflammatory cytokine IL-10 [18-20]. Of note, recent studies have revealed that IL-27 exerts potent antitumor effects against various tumor models via different mechanisms, including $\mathrm{CD}^{+} \mathrm{T}$ cells, natural killer (NK) cells, antibody-dependent cell-mediated cytotoxicity (ADCC), antiangiogenesis, direct suppression of tumor growth, and inhibition of cychroxygenase-2 (COX-2) expression, depending on the characteristic of each tumor [21-25].

The associations between polymorphisms of $I L-27$ gene, as well as serum/plasma levels of IL-27 and various human disorders including asthma, inflammatory bowel diseases, chronic obstructive pulmonary disease (COPD), colorectal cancer, esophageal cancer, and glioma have been studied [26-33]. Accordingly, the present study analyzed the influence of $I L-27$ polymorphisms and plasma levels of IL-27 on the susceptibility to bladder cancer and prognosis of patients.

\section{Methods}

\section{Study subjects}

A hospital-based case-control study was conducted including 332 unrelated patients with transitional cell carcinoma of bladder between 2006 and 2010 derived from the West China Hospital of Sichuan University. The diagnosis of bladder cancer was confirmed in all cases by histological examination of tissue from resected specimens. Clinical and follow-up data were abstracted from patients' medical records and by telephone calls. The control group consisted of 499 healthy subjects from a routine health survey in the same hospital. Table 1 summarized the baseline clinical characteristics of the patients and control groups. Those patients who had previous cancer, previous radiotherapy or chemotherapy, and metastasized cancer from other or unknown origins were excluded. Control subjects were genetically unrelated individuals and those with any personal or family history of bladder cancer or other serious disease were intentionally excluded. All subjects were Han population living in Sichuan province of southwest China. This study was approved by the ethics committee of West China Second University Hospital and all subjects gave written informed consent to participate.

\section{DNA extraction and genotyping}

Two single nucleotide polymorphisms (SNPs), rs153109 (also known as -964 A/G) and rs17855750 (also known as $2905 \mathrm{~T} / \mathrm{G}$ ), were genotyped in the present study. Genomic DNA of each individual was extracted from $200 \mu \mathrm{l}$ EDTAanticoagulated peripheral blood samples by a DNA isolation kit from Bioteke (Peking, China) and the procedure was performed according to the manufacturer's instructions. Genotyping was performed using the polymerase chain reaction $(\mathrm{PCR})$-restriction fragment length polymorphism (RFLP) method. Primers were established with the PIRA PCR designer (http://primer1.soton.ac.uk/

Table 1 Characteristics of the study population

\begin{tabular}{llll}
\hline & NMIBC group & MIBC group & Controls \\
\hline Sex & & & \\
Male & $137(77.8)$ & $126(80.8)$ & $381(76.4)$ \\
Female & $39(22.2)$ & $30(19.2)$ & $118(23.6)$ \\
$\begin{array}{l}\text { Age at first diagnosis } \\
\text { (mean } \pm \text { SD) }\end{array}$ & $61.96 \pm 12.88$ & $65.85 \pm 10.98$ & $64.51 \pm 5.71$ \\
Smoking status & & & \\
Smokers & $90(51.1)$ & $85(54.5)$ & $241(48.3)$ \\
Non-smokers & $86(48.9)$ & $71(45.5)$ & $258(51.7)$ \\
Clinical stage & & & \\
Ta & $10(5.7)$ & - & - \\
T1 & $166(94.3)$ & - & - \\
T2 & - & $91(58.3)$ & - \\
T3a & - & $36(23.1)$ & - \\
T3b & - & $18(11.5)$ & - \\
T4 & - & $11(7.1)$ & - \\
Tumor grade & & & \\
Low grade & $119(67.6)$ & $25(16.0)$ & - \\
High grade & $57(32.4)$ & $131(84.0)$ & - \\
\hline & & & \\
\hline
\end{tabular}


primer2.html) [34]. In brief, the primer sequences were: F: 5' -CTGATCCTGACCTCACTCAACGC-3' and R: 5' CTGACTGGGACTGGGACTCAGC-3' for rs153109. The primers used for amplification of rs17855750 were F: 5' -ATCTCGCCAGGAAGCTGCGC-3' and R: 5' CTGTTAGTGGGGGCCAGAAGGGA-3' .

DNA fragments containing the polymorphisms were amplified in a total volume of $25 \mu \mathrm{l}$, including $2.5 \mu \mathrm{l} \mathrm{10 \times}$ PCR buffer, $1.5 \mathrm{mmol} / \mathrm{L} \mathrm{MgCl}_{2}, 0.15 \mathrm{mmol} / \mathrm{L}$ dNTPs, $0.5 \mu \mathrm{mol} / \mathrm{L}$ each primer, $100 \mathrm{ng}$ of genomic DNA and $1 \mathrm{U}$ of Taq DNA polymerase. The PCR conditions were $94{ }^{\circ} \mathrm{C}$ for $4 \mathrm{~min}$, followed by 32 cycles of $30 \mathrm{~s}$ at $94{ }^{\circ} \mathrm{C}, 30 \mathrm{~s}$ at $64{ }^{\circ} \mathrm{C}$ for rs 153109 and $66^{\circ} \mathrm{C}$ for rs 17855750 , and $30 \mathrm{~s}$ at $72{ }^{\circ} \mathrm{C}$, with a final elongation at $72{ }^{\circ} \mathrm{C}$ for $10 \mathrm{~min}$. PCR products were digested overnight with specific restriction enzyme and the digested products were separated by a $6 \%$ polyacrylamide gel and stained with $1.5 \mathrm{~g} / \mathrm{L}$ argent nitrate: PaeR7I for rs153109, allele G is cuttable, yielding two fragments of $45 \mathrm{bp}$ and $179 \mathrm{bp}$, allele A is uncuttable and the fragment is still $224 \mathrm{bp}$; and BstUI for rs17855750, allele G is cuttable, yielding two fragments of $19 \mathrm{bp}$ and $101 \mathrm{bp}$, allele $\mathrm{T}$ is uncuttable and the fragment is still $120 \mathrm{bp}$. The genotypes were confirmed by the DNA sequencing analysis. About $10 \%$ of the samples were randomly selected to perform the repeated assays and the results were $100 \%$ concordant.

\section{Plasma IL-27 determination}

For quantitative determination of IL-27, peripheral blood from 124 patients (NMIBC/MIBC: 50/74; male/female: 96/28) and 151 controls (male/female: 115/36) was collected into vaccutainer tubes containing EDTAanticoagulant. Samples were centrifuged at $3000 \times \mathrm{g}$ for $10 \mathrm{~min}$ and plasma was collected and stored at $-80{ }^{\circ} \mathrm{C}$ until use. Plasma levels of IL-27 were measured using commercially available enzyme-linked immunosorbent assay (ELISA) kits (USCNLIFE, Houston City, TX) according to the manufacturer's instructions. Developed color reaction was measured as OD450 units on a multimode microplate reader (TECAN Infinite M200, Switzerland). The plasma concentration of IL-27 was determined using standard curve constructed with the kit's standards over the range of $0-1000 \mathrm{pg} / \mathrm{mL}$. The minimum detectable dose of IL-27 was typically less than $5.9 \mathrm{pg} / \mathrm{mL}$.

\section{Statistical analyses}

Data were analyzed using SPSS for Windows software package version 13.0 (SPSS Inc., Chicago, IL, USA). Genotype frequencies of these two SNPs were obtained by directed counting and Hardy-Weinberg equilibrium was evaluated by chi-square test. Odds ratio (OR) and respective $95 \%$ confidence intervals $(\mathrm{CI})$ were reported to evaluate the effects of any difference. Probability values of 0.05 or less were regarded as statistically significant, and all statistical tests were two sided. Genotypic association test in a case-control pattern assuming codominant, dominant, recessive, or overdominant genetic models was performed using SNPstats [35]. Allelic association was performed by chi-square test. The plasma IL-27 levels in patients with different $I L-27$ SNPs genotype, and among NMIBC, MIBC and controls were compared using the non-parametric Kruskal-Wallis test. Tukey test was used for pairwise test. Mann Whitney test was used to compare plasma levels of IL-27 of subgroups (age at first diagnosis, sex, smoking status and tumor grade).

Kaplan-Meier plots and the log-rank test were used to evaluate the association between genotypes of $I L-27$ SNPs, plasma IL-27 levels with patients' outcome from the date of primary diagnosis until recurrence or death. Multivariate survival analysis for the influence of $I L-27$ SNPs and plasma IL-27 levels on patients' outcome was carried out by Cox regression analysis adjusted by the effect of age at first diagnosis, sex and smoking status. Hazard ratio (HR) and $95 \%$ CI were calculated from the Cox regression model including all factors for multiple analysis.

\section{Results}

\section{IL-27 SNPs and susceptibility to bladder cancer}

These two SNPs of $I L-27$, rs153109 and rs17855750, were successfully genotyped in 332 patients with bladder cancer and 499 control subjects. Three genotypes of each SNP were identified and the genotypes were confirmed by the DNA sequencing analysis. All observed genotype frequencies in both patients and controls were in agreement with that expected under the Hardy-Weinberg equilibrium. Genotype distributions and allele frequencies of $I L-27$ SNPs in patients and controls are shown in Table 2. Significant difference in genotype frequency distributions of rs153109 was observed between bladder cancer patients and controls $(P=0.029, \mathrm{OR}=1.37,95 \% \mathrm{CI}=1.03-1.82$ for rs153109 in the dominant genetic model). For rs17855750, no GG genotype was observed in 499 controls, while there were 4 patients carrying GG in 322 patients, suggesting that rs17855750 may be associated with increased risk for bladder cancer in a recessive genetic model $(P=0.006)$. There were no statistically significant differences between patients and controls in terms of the allele frequency distribution of rs153109 and rs17855750.

\section{IL-27 SNPs and patients' characteristics}

To further explore the effects of $I L-27$ SNPs on bladder carcinogenesis, we conducted the stratified analyses. Genotypic distributions of rs153109 and rs17855750 between NMIBC and MIBC patients are shown in Table 3. No significant difference for the distribution of rs153109 between NMIBC and MIBC was observed. Compared to 
Table 2 Distribution of SNPs in IL-27 among patients and controls and their association with bladder cancer risk

\begin{tabular}{|c|c|c|c|c|c|c|c|c|c|c|}
\hline \multirow{3}{*}{ Model } & \multirow{3}{*}{ Genotype } & \multicolumn{4}{|l|}{ rs153109 } & \multicolumn{5}{|l|}{ rs17855750 } \\
\hline & & \multirow{2}{*}{$\begin{array}{l}\text { Controls } \\
N=499(\%)\end{array}$} & \multirow{2}{*}{$\begin{array}{l}\text { patients } \\
N=332(\%)\end{array}$} & \multirow[t]{2}{*}{$\mathrm{OR}(95 \% \mathrm{Cl})^{\mathrm{a}}$} & \multirow[t]{2}{*}{$P$ value $^{a}$} & \multirow[t]{2}{*}{ Genotype } & \multirow{2}{*}{$\begin{array}{l}\text { Controls } \\
N=499(\%)\end{array}$} & \multirow{2}{*}{$\begin{array}{l}\text { patients } \\
N=332(\%)\end{array}$} & \multirow[t]{2}{*}{ OR $(95 \% \mathrm{Cl})^{\mathrm{a}}$} & \multirow[t]{2}{*}{$P$ value } \\
\hline & & & & & & & & & & \\
\hline \multirow[t]{3}{*}{ Codominant } & $\mathrm{AA}$ & $229(45.9)$ & $127(38.2 \%)$ & 1.00 (reference) & 0.075 & $\pi$ & $421(84.4)$ & $275(82.8 \%)$ & 1.00 (reference) & 0.022 \\
\hline & $A G$ & 204 (40.9) & $160(48.2 \%)$ & $1.41(1.05-1.92)$ & & TG & 78 (15.6) & 53 (16.0\%) & $0.97(0.66-1.42)$ & \\
\hline & GG & 66 (13.2) & 45 (13.6\%) & $1.23(0.79-1.89)$ & & GG & 0 & $4(1.2 \%)$ & $0.00(0.00-\mathrm{NA})$ & \\
\hline \multirow[t]{2}{*}{ Dominant } & AA & $229(45.9)$ & $127(38.2 \%)$ & 1.00 (reference) & 0.029 & $\pi$ & $421(84.4)$ & $275(82.8 \%)$ & 1.00 (reference) & 0.57 \\
\hline & $A G / G G$ & $270(54.1)$ & $205(61.8 \%)$ & $1.37(1.03-1.82)$ & & $\mathrm{TG} / \mathrm{GG}$ & 78 (15.6) & 57 (17.2\%) & $0.90(0.62-1.31)$ & \\
\hline \multirow[t]{2}{*}{ Recessive } & AA/AG & $433(86.8)$ & $287(86.5 \%)$ & 1.00 (reference) & 0.9 & TT/TG & 499 (100) & $328(98.8 \%)$ & 1.00 (reference) & 0.006 \\
\hline & GG & $66(13.2)$ & 45 (13.6\%) & $1.03(0.68-1.54)$ & & GG & $0(0)$ & $4(1.2 \%)$ & $0.00(0.00-N A)$ & \\
\hline \multirow[t]{5}{*}{ Overdominant } & $\mathrm{AA} / \mathrm{GG}$ & $295(59.1)$ & $172(51.8 \%)$ & 1.00 (reference) & 0.037 & $T T / G G$ & $421(84.4)$ & $279(84.0 \%)$ & 1.00 (reference) & 0.92 \\
\hline & $A G$ & $204(40.9)$ & $160(48.2 \%)$ & $1.35(1.02-1.79)$ & & TG & 78 (15.6) & 53 (16.0\%) & $0.98(0.59-1.19)$ & \\
\hline & Allele & & & & & & & & & \\
\hline & A & $662(66.3)$ & $414(62.3)$ & $1.19(0.97-1.46)$ & 0.096 & $\mathrm{~T}$ & $920(92.2)$ & $603(90.8)$ & $1.20(0.84-1.70)$ & 0.317 \\
\hline & G & $336(33.7)$ & $250(37.7)$ & & & G & $78(7.8)$ & $61(9.2)$ & & \\
\hline
\end{tabular}

$N$ corresponds to the number of individuals

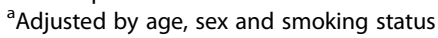

Boldfaced values indicate a significant difference at the $5 \%$ level

NMIBC, the TG/GG genotypes of rs17855750 were associated with an increased risk for MIBC $(P=0.042)$.

\section{Plasma IL-27 levels with susceptibility to bladder cancer} and IL-27 genotype

As shown in Fig. 1 and Table 4, by analyzing the plasma IL27 concentration of 124 bladder cancer patients and 151 controls, we found significant difference among NMIBC, MIBC and controls $(P<0.0001)$. Results of Tukey's Multiple
Comparison Test showed IL-27 levels of NMIBC patients $(21.16 \pm 2.91 \mathrm{pg} / \mathrm{ml})$ were significantly decreased compared with controls $(38.21 \pm 2.56 \mathrm{pg} / \mathrm{ml})$. Although the IL-27 levels of MIBC patients $(27.34 \pm 5.72 \mathrm{pg} / \mathrm{ml})$ were lower than that of controls, the difference was not statistically significant. There was no statistically significant difference for plasma IL-27 levels between NMIBC and MIBC patients.

To study the association between genotype and phenotype, plasma IL-27 concentration in patients with respect to $I L-27$ SNPs was investigated. As shown in Table 4, no

Table 3 Distribution of SNPs in IL-27 among NMIBC and MIBC patients

\begin{tabular}{|c|c|c|c|c|c|c|c|c|c|c|}
\hline \multirow{3}{*}{ Model } & \multirow{3}{*}{ Genotype } & \multicolumn{4}{|l|}{ rs153109 } & \multicolumn{5}{|l|}{ rs 17855750} \\
\hline & & \multirow{2}{*}{$\begin{array}{l}\text { NMIBC } \\
N=176(\%)\end{array}$} & \multirow{2}{*}{$\begin{array}{l}\text { MIBC } \\
N=156(\%)\end{array}$} & \multirow[t]{2}{*}{ OR $(95 \% C l)^{a}$} & \multirow[t]{2}{*}{$P$ value $^{\mathrm{a}}$} & \multirow[t]{2}{*}{ Genotype } & \multirow{2}{*}{$\begin{array}{l}\text { NMIBC } \\
N=176(\%)\end{array}$} & \multirow{2}{*}{$\begin{array}{l}\text { MIBC } \\
N=156(\%)\end{array}$} & \multirow[t]{2}{*}{ OR $(95 \% C l)^{a}$} & \multirow[t]{2}{*}{$P$ value } \\
\hline & & & & & & & & & & \\
\hline \multirow[t]{3}{*}{ Codominant } & AA & 66 (37.5 \%) & 61 (39.1\%) & 1.00 (reference) & 0.99 & $\pi$ & 149 (84.7 \%) & $126(80.8 \%)$ & 1.00 (reference) & 0.076 \\
\hline & $A G$ & 87 (49.4 \%) & $73(46.8 \%)$ & $1.04(0.60-1.81)$ & & TG & $26(14.8 \%)$ & $27(17.3 \%)$ & $0.53(0.26-1.09)$ & \\
\hline & GG & 23 (13.1\%) & 22 (14.1\%) & $1.02(0.46-2.27)$ & & GG & $1(0.6 \%)$ & $3(1.9 \%)$ & $0.15(0.01-1.84)$ & \\
\hline \multirow[t]{2}{*}{ Dominant } & AA & 66 (37.5 \%) & 61 (39.1\%) & 1.00 (reference) & 0.88 & $\pi$ & 149 (84.7 \%) & $126(80.8 \%)$ & 1.00 (reference) & 0.042 \\
\hline & $\mathrm{AG} / \mathrm{GG}$ & $110(62.5 \%)$ & 95 (60.9 \%) & $1.04(0.62-1.75)$ & & $\mathrm{TG} / \mathrm{GG}$ & 27 (15.3\%) & 30 (19.2 \%) & $2.04(1.02-4.17)$ & \\
\hline \multirow[t]{2}{*}{ Recessive } & $\mathrm{AA} / \mathrm{AG}$ & 153 (86.9 \%) & 134 (85.9\%) & 1.00 (reference) & 0.99 & TT/TG & 175 (99.4 \%) & $153(98.1 \%)$ & 1.00 (reference) & 0.14 \\
\hline & GG & $23(13.1 \%)$ & 22 (14.1\%) & $1.00(0.48-2.09)$ & & GG & $1(0.6 \%)$ & $3(1.9 \%)$ & $0.17(0.01-2.07)$ & \\
\hline \multirow[t]{5}{*}{ Overdominant } & $\mathrm{AA} / \mathrm{GG}$ & 89 (50.6 \%) & $83(53.2 \%)$ & 1.00 (reference) & 0.88 & $T / G G$ & $150(85.2 \%)$ & $129(82.7 \%)$ & 1.00 (reference) & 0.1 \\
\hline & $A G$ & 87 (49.4 \%) & 73 (46.8 \%) & $1.04(0.63-1.73)$ & & $\mathrm{TG}$ & 26 (14.8 \%) & $27(17.3 \%)$ & $0.55(0.27-1.13)$ & \\
\hline & Allele & & & & & & & & & \\
\hline & A & 219 (62.2) & $195(62.5)$ & $0.99(0.72-1.35)$ & 0.94 & T & $324(92.0)$ & $279(89.4)$ & $1.37(0.81-2.32)$ & 0.28 \\
\hline & G & $133(37.8)$ & 117 (37.5) & & & G & $28(8.0)$ & 33 (10.6) & & \\
\hline
\end{tabular}

$N$ corresponds to the number of individuals

${ }^{a}$ Adjusted by age, sex and smoking status

Boldfaced values indicate a significant difference at the $5 \%$ level 


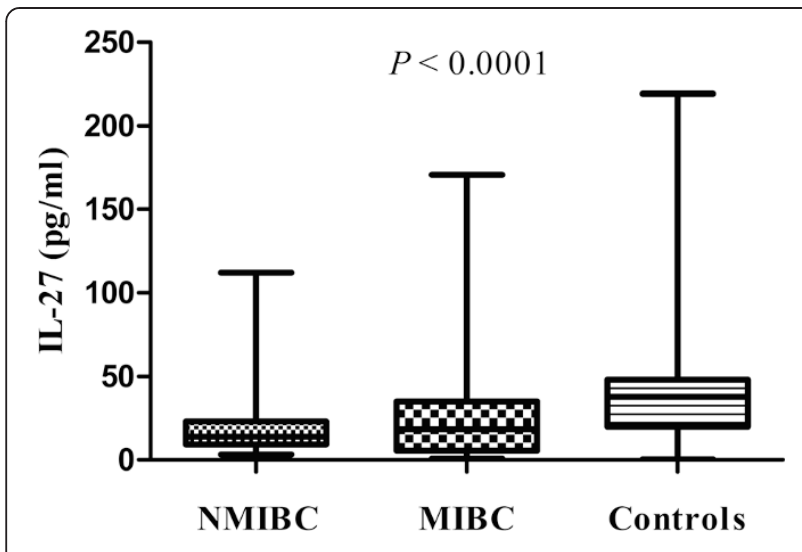

Fig. 1 Plasma levels of IL-27 in NMIBC, MIBC patients and controls

Table 4 Relationship between plasma levels of IL-27 and patients' characteristics

\begin{tabular}{|c|c|c|c|c|c|c|}
\hline \multirow[t]{2}{*}{ Variable analyzed } & \multicolumn{4}{|c|}{ IL-27 (pg/ml) } & \multirow[b]{2}{*}{ Median } & \multirow[b]{2}{*}{$P$} \\
\hline & Total, N & Mean & SD & SEM & & \\
\hline \multicolumn{7}{|l|}{ Case-control } \\
\hline Controls & 151 & 38.21 & 28.76 & 2.56 & 37.80 & $<0.0001$ \\
\hline NMIBC & 74 & 21.16 & 21.92 & 2.91 & 13.91 & \\
\hline $\mathrm{MIBC}$ & 50 & 27.34 & 32.87 & 5.72 & 18.41 & \\
\hline \multicolumn{7}{|l|}{$\operatorname{Age}^{a}$} \\
\hline$\leq 65$ & 88 & 26.49 & 32.23 & 4.8 & 16.33 & 0.94 \\
\hline$>65$ & 36 & 20.36 & 18.91 & 2.82 & 15.29 & \\
\hline \multicolumn{7}{|l|}{ Sex } \\
\hline Male & 96 & 24.13 & 27.14 & 3.22 & 16.33 & 0.43 \\
\hline Female & 28 & 20.81 & 24.20 & 5.55 & 15.04 & \\
\hline \multicolumn{7}{|l|}{ Smoking status } \\
\hline Smokers & 73 & 22.86 & 25.80 & 3.42 & 16.33 & 0.55 \\
\hline Non-smokers & 51 & 24.40 & 27.93 & 4.86 & 13.61 & \\
\hline \multicolumn{7}{|l|}{ Tumor grade } \\
\hline Low grade & 53 & 18.63 & 19.36 & 2.99 & 12.99 & 0.058 \\
\hline High grade & 71 & 27.62 & 30.97 & 4.47 & 17.85 & \\
\hline \multicolumn{7}{|l|}{ rs153109 } \\
\hline AA & 41 & 20.99 & 18.68 & 3.47 & 15.66 & 0.69 \\
\hline$A G$ & 61 & 26.07 & 31.37 & 4.44 & 15.69 & \\
\hline GG & 22 & 17.80 & 18.45 & 5.56 & 13.51 & \\
\hline \multicolumn{7}{|l|}{ rs17855750 } \\
\hline$\pi$ & 101 & 25.11 & 28.21 & 3.35 & 15.66 & 0.055 \\
\hline $\mathrm{TG}$ & 20 & 17.13 & 17.64 & 4.05 & 10.93 & \\
\hline $\mathrm{GG}^{\mathrm{b}}$ & 3 & - & - & - & - & \\
\hline
\end{tabular}

$N$ corresponds to the number of individuals

${ }^{a}$ The threshold for age is based on median of bladder cancer patients

${ }^{b}$ Plasma IL-27 levels for all of these 3 samples were under the detection threshold for the present ELISA kits and their value was conservative determined as $5.9 \mathrm{pg} / \mathrm{mL}$, which is the minimum detectable dose of IL-27 for the kits used in the present study significant association between plasma IL-27 levels and genotype of rs153109 was observed. Interestingly, plasma IL-27 levels for all of the 3 samples in rs17855750 GG group were under the detection threshold for the present ELISA kits and their value was conservative determined as $5.9 \mathrm{pg} / \mathrm{mL}$, which is the minimum detectable dose of IL-27 for the kits used in the present study. Furthermore, the plasma IL-27 levels in patients with homozygous TT genotype were higher than that of heterozygous TG genotype, suggesting that genotype of rs17855750 may be associated with plasma IL-27 levels with an apparent gene-dose effect, although not statistically significant with a borderline $P=0.055$.

No statistically significant association was found between plasma levels of IL-27 and patients' characteristics including age, sex, or smoking status (Table 4). While the plasma IL-27 levels of patients with high grade (27.62 \pm $4.47 \mathrm{pg} / \mathrm{mL}, \mathrm{n}=71$ ) were higher than that of low grade $(18.63 \pm 2.99 \mathrm{pg} / \mathrm{mL}, \mathrm{n}=53)$, although not statistically significant $(P=0.058)$.

\section{IL-27 SNPs, plasma IL-27 levels and outcome}

There were 332 bladder cancer patients included in this study. During the follow-up period, 51 patients (NMIBC: 13/176, MIBC: 38/156) had died and 281 patients alive (NMIBC: 163/176, MIBC: 118/156), and 97 patients (NMIBC: 50/176, MIBC: 47/156) had recurrence. The age of the patients who were dead was $69.22 \pm 9.89$ years compared with $62.80 \pm 12.29$ years in surviving patients $(P<0.001)$, and $65.03 \pm 11.35$ years in recurrent patients compared with $63.28 \pm 12.47$ years in non-recurrent patients $(P=0.23)$. As it's well known that patients with NMIBC have a better prognosis than patients with MIBC, survival analysis were conducted in these different populations independently.

IL-27 genotypes were subjected to multivariate survival analysis adjusted by age at first diagnosis, sex and smoking status (Table 5). No significant effect for rs153109 on overall survival or recurrence-free survival, and for rs17855750 on recurrence-free survival of both NMIBC and MIBC patients was observed. Interestingly, rs17855750 may be an independent protective factor for overall survival in patients with MIBC. In the dominant genetic model, univariate survival analysis indicated that MIBC patients with allele G (TG/GG genotype) had a significantly decreased risk for death than patients without allele $\mathrm{G}$ (TT genotype) $(\mathrm{HR}=0.21,95 \% \mathrm{CI}=0.05-0.90, P=0.035)$ (Fig. 2). However, there was no association between rs17855750 and overall survival of NMIBC patients (Fig. 3).

The association between plasma IL-27 levels and survival was analyzed in 124 patients (NMIBC: 74, MIBC: 50). During the follow-up period, 26 patients (NMIBC: 8/74, MIBC: 18/50) had died and 37 patients (NMIBC: 21/74, MIBC: 16/50) had recurrence. According 
Table 5 Association between SNPs in IL-27 and patient's survival

\begin{tabular}{|c|c|c|c|c|c|c|c|c|c|c|c|c|}
\hline \multirow[t]{2}{*}{ SNP/genotype } & \multicolumn{6}{|c|}{ NMIBC } & \multirow[b]{2}{*}{ Alive/dead, $N$} & \multirow[b]{2}{*}{$\mathrm{HR}(95 \% \mathrm{Cl})^{\mathrm{a}}$} & \multirow[b]{2}{*}{ P } & \multicolumn{3}{|l|}{ MIBC } \\
\hline & Alive/dead, N & $\mathrm{HR}(95 \% \mathrm{Cl})^{\mathrm{a}}$ & $P$ & Recurrence/Non-recurrence & $\mathrm{HR}(95 \% \mathrm{Cl})^{\mathrm{a}}$ & $P$ & & & & Recurrence/Non-recurrence & $\mathrm{HR}(95 \% \mathrm{Cl})^{\mathrm{a}}$ & $P$ \\
\hline \multicolumn{13}{|l|}{ rs153109 } \\
\hline AA & $60 / 6$ & & & $44 / 22$ & & & $41 / 20$ & & & $39 / 22$ & & \\
\hline$A G$ & $82 / 5$ & & & $64 / 23$ & & & $58 / 15$ & & & $55 / 18$ & & \\
\hline GG & $21 / 2$ & & & $18 / 5$ & & & $19 / 3$ & & & $15 / 7$ & & \\
\hline Dominant & & $1.58(0.53-4.72)$ & 0.41 & & $1.49(0.85-2.60)$ & 0.17 & & $1.76(0.93-3.33)$ & 0.09 & & $1.25(0.70-2.23)$ & 0.46 \\
\hline Recessive & & $1.02(0.22-4.69)$ & 0.98 & & $0.68(0.27-1.74)$ & 0.42 & & $0.42(0.13-1.38)$ & 0.15 & & $0.91(0.40-2.07)$ & 0.82 \\
\hline \multicolumn{13}{|l|}{ Overdominant } \\
\hline \multicolumn{13}{|l|}{ rs17855750 } \\
\hline$\pi$ & $137 / 12$ & & & $105 / 44$ & & & $90 / 36$ & & & $87 / 39$ & & \\
\hline TG & $25 / 1$ & & & $20 / 6$ & & & $26 / 1$ & & & $20 / 7$ & & \\
\hline GG & $1 / 0$ & & & $1 / 0$ & & & $2 / 1$ & & & $2 / 1$ & & \\
\hline Dominant & & $0.39(0.05-3.10)$ & 0.37 & & $0.59(0.24-1.42)$ & 0.24 & & $0.21(0.05-0.90)$ & 0.035 & & $0.81(0.37-1.77)$ & 0.60 \\
\hline Recessive & & $0(0-N A)$ & 0.99 & & 0 (O-NA) & 0.97 & & $1.09(0.14-8.45)$ & 0.94 & & $1.40(0.18-10.76)$ & 0.75 \\
\hline & & $0.42(0.05-3.35)$ & 0.41 & & $0.61(0.25-1.49$ & 0.28 & & $0.12(0.02-0.88)$ & 0.037 & & $0.76(0.33-1.74)$ & 0.52 \\
\hline
\end{tabular}

$N$ corresponds to the number of individuals

${ }^{a}$ Adjusted by age, sex and smoking status

Boldfaced values indicate a significant difference at the $5 \%$ level 


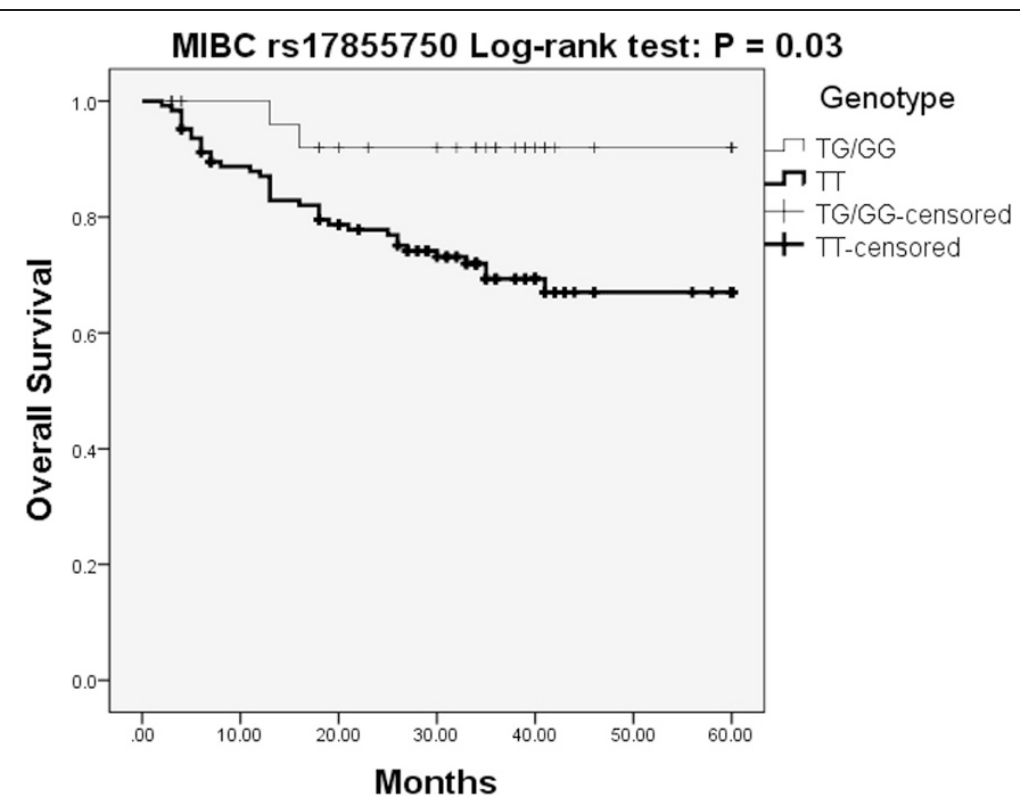

Fig. 2 Kaplan-Meier overall survival curve for MIBC patients based on rs17855750 genotypes

to their respective median plasma IL-27 levels, $13.91 \mathrm{pg} /$ $\mathrm{ml}$ for NMIBC and $18.41 \mathrm{pg} / \mathrm{ml}$ for MIBC, NMIBC and MIBC patients were divided into two subgroups, and the association of plasma IL-27 levels with survival was analyzed, respectively. We didn't find any influence for the plasma IL-27 levels on patients' survival.

\section{Discussion}

In the present study, we have identified significant associations between $I L-27$ SNPs and susceptibility to bladder cancer, patients' characteristics, and overall survival of patients with MIBC. The association between different genotype of rs17855750 and plasma IL-27 levels, and significantly reduced plasma IL-27 levels compared to controls has also been observed.

IL-27, composed of the EBI3 and IL-27p28 subunits, is a member of the IL-12 family. EBI3 subunit was first identified from a subtractive hybridization screen of genes expressed in EBV transformed B cell lines in 1996 [36]. As a consequence of a computational approach to

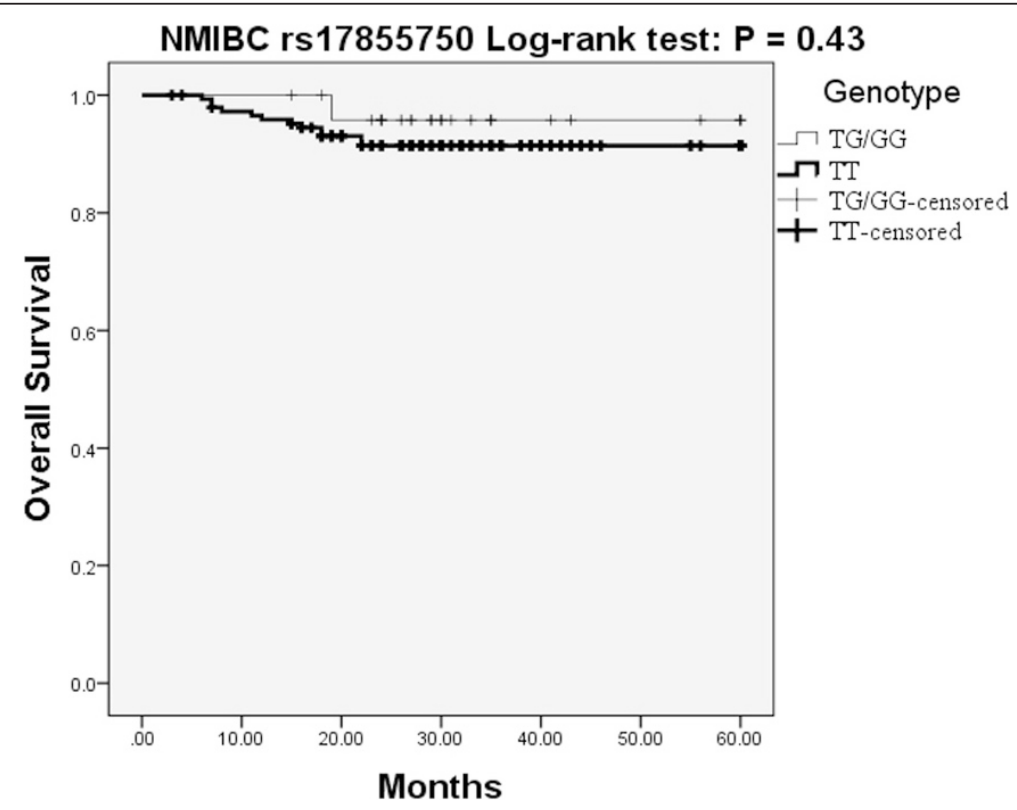

Fig. 3 Kaplan-Meier overall survival curve for NMIBC patients based on rs17855750 genotypes 
identify novel $\alpha$-helical cytokines of the IL- 6 family, the IL-27p28 subunit was recognized as the partner for EBI3 [17]. IL-27 could synergize with IL-12 to promote proliferation of naïve $\mathrm{CD} 4^{+} \mathrm{T}$ cells, but not memory $\mathrm{CD} 4^{+} \mathrm{T}$ cells, and the production of IFN- $\gamma$ from NK cells and $\mathrm{CD} 4^{+} \mathrm{T}$ cells, suggesting that IL-27 function as a proinflammatory cytokine $[17,37]$. Subsequent studies have revealed the pleiotropic properties of IL-27 that can limit or enhance ongoing immune responses depending on context.

It has been 10 years since the first report on the antitumor activity of IL-27 against a murine tumor model of colon carcinoma C26, which suggested that IL-27 has potent abilities to induce tumor-specific antitumor activity and protective immunity and that the antitumor activity is mediated mainly through $\mathrm{CD}^{+} \mathrm{T}$ cells, IFN- $\gamma$, and T-bet but not through STAT4 [24]. In the same year, results from TBJ murine neuroblastoma tumors also demonstrated that IL-27 has a potent ability to induce tumorspecific antitumor and protective immunity [38]. Since then, the last decade has seen the description of the signaling pathways engaged by IL-27, and an appreciation has emerged that IL-27 can modulate the intensity and duration of many classes of T cell responses [16]. IL-27 mediated antitumor mechanisms are complex, alone or in combination with other cytokines, IL-27 boosts antitumor immunity by contributing to the development of NK cells and cytotoxic T cells (CTLs), and by exerting potent antiangiogenic and antimetastatic activities [21].

The associations between polymorphisms of $I L-27$ gene and human diseases, including cancers, have been widely studied [32, 33]. The SNP rs153109 has been reported to be associated with susceptibility to asthma and inflammatory bowel diseases in a Korean population, and with chronic obstructive pulmonary disease in a Chinese population, respectively [26-28]. Although no association between IL-27 polymorphisms and immune thrombocytopenia, esophageal cancer, glioma, type 1 diabetes, or nasopharyngeal was observed in previous reports, our recent study suggested that $I L-27$ gene polymorphisms may play important roles in the susceptibility to epithelial ovarian cancer $[30,31,39-42]$. The present study identified that $I L-27$ gene is associated with susceptibility to bladder cancer. Furthermore, SNP rs17855750 turned out to be a protective factor for overall survival in patients with MIBC. For the first time, our data suggested that polymorphisms of $I L-27$ gene may play important roles in the initiation, promotion, and progression of bladder cancer, especially in MIBC.

To date, few studies have reported the associations between serum/plasma IL-27 levels and human diseases. Although there was no association between $I L-27$ gene polymorphisms and glioma, the serum IL-27 levels were decreased in glioma patients compared with controls. Moreover, the authors reported that $I L-12$ gene 16974
$\mathrm{A} / \mathrm{C}$ polymorphism may regulate the expression of the serum IL-12 and IL-27, but there were no significant associations of the $I L-27$ gene polymorphisms with serum levels of IL-27 [31]. It has also been reported that serum/plasma levels of IL-27 decreased in epithelial ovarian cancer, while increased in cutaneous $\mathrm{T}$-cell lymphoma, primary immune thrombocytopenia (ITP), and gastroesophageal cancer [41, 43-45]. Interestingly, although no significant association of rs153109 with plasma levels of IL-27 was observed, our present data indicated that genotype of rs17855750 may be associated with plasma IL-27 levels with an apparent gene-dose effect. Furthermore, plasma IL-27 levels for all of the 3 GG homozygous subjects which were identified only in the case group were under the detection threshold. The plasma levels of IL-27 among NMIBC, MIBC and controls were significantly different, especially IL-27 levels of NMIBC were significantly decreased compared with controls. While there was no difference between NMIBC and MIBC, or between MIBC and controls. We didn't find any influence of plasma IL-27 levels on the survival of patients, the present data suggested that decreased plasma IL-27 levels may be associated with increased susceptibility to bladder cancer.

A growing body of evidence has validated the protective role of physiological levels of IL-27 against the development and progression of carcinogen- and transgene-driven neoplasms [22]. As it appears to have been associated with reduced toxicity, IL-27 might be advantageous over other cytokines in view of potential clinical applications [23]. No study of IL-27 on bladder cancer has been reported, but IL-27 has been reported to be effective in reducing tumor growth and can promote enhanced accumulation of effector cells in prostate tumors [46].

Taken together, the present study suggests that $I L-27$ gene polymorphisms are associated with susceptibility to bladder cancer. The SNP rs17855750 may have a dual role as both a predictor of bladder cancer and a prognostic marker for patients' survival. The decreased plasma levels of IL-27 compared to controls observed in our present study reinforces this predictive role as a marker of bladder cancer.

\section{Conclusions}

In conclusion, although our findings should be interpreted cautiously due to the limited number of patients studied and sparse data, our present data lead us to speculate that the assessment of IL-27 gene polymorphisms and plasma levels may be useful for predicting susceptibility to bladder cancer and patients' outcome. Further studies with a larger number of patients and IL27 gene therapy in bladder cancer cells are warranted to confirm these results. 


\section{Competing interests}

The authors declare that they have no competing interests.

\section{Authors' contributions}

BZ, PZ and LZ conceived of the study, participated in its design, carried out most of the experiments and drafted the manuscript. PZ, $\Pi$, and LZ participated in design of study and helped to draft the manuscript. PZ, $T$, $\mathrm{HL}$ and YS performed sample collection. BZ, KZ, YP, PC and YS participated in DNA extraction and genotyping. BZ did the statistics. All authors have read and approved the final manuscript.

\section{Authors' information}

Dr. Bin Zhou is the submitting author.

\section{Acknowledgements}

This work was supported by the National Natural Science Foundation of China (No. 81172440, No. 81172494, No. 81272821 and No. 81202023); the Applied Basic Research Programs of Science and Technology Commission Foundation of Sichuan Province (No. 2012SZ0008); and the Science Foundation for The Excellent Youth Scholars of Sichuan University (No. 2011SCU04A16)

\section{Author details}

${ }^{1}$ Laboratory of Molecular Translational Medicine, West China Institute of Women and Children's Health, Key Laboratory of Obstetric \& Gynecologic and Pediatric Diseases and Birth Defects of Ministry of Education, West China Second University Hospital, Sichuan University, Chengdu, Sichuan, P R China. ${ }^{2}$ Department of Urology, West China Hospital, Sichuan University, Chengdu, Sichuan, P R China. ${ }^{3}$ Department of Urology, Affiliated Hospital of North Sichuan Medical College, Nanchong, Sichuan, P R China. ${ }^{4}$ Department of Urology, Institute of oncology, the Second People's Hospital of Sichuan, Chengdu, P R China. ${ }^{5}$ Department of Forensic Biology, West China School of Preclinical and Forensic Medicine, Sichuan University, Chengdu, Sichuan, P R China.

\section{Received: 13 August 2014 Accepted: 21 May 2015}

Published online: 27 May 2015

\section{References}

1. Siegel R, Naishadham D, Jemal A. Cancer statistics, 2013. CA Cancer J Clin. 2013;63(1):11-30.

2. Cancer Incidence in Five Continents. Volume IX. Geneva, Switzerland: WHO Press. IARC scientific publications 2008(160):1-837.

3. Volanis D, Kadiyska T, Galanis A, Delakas D, Logotheti S, Zoumpourlis V. Environmental factors and genetic susceptibility promote urinary bladder cancer. Toxicol Lett. 2010;193(2):131-7.

4. Hanahan D, Weinberg RA. The hallmarks of cancer. Cell. 2000;100(1):57-70.

5. Hanahan D, Weinberg RA. Hallmarks of cancer: the next generation. Cell. 2011;144(5):646-74.

6. Coussens LM, Werb Z. Inflammation and cancer. Nature. 2002;420(6917):860-7.

7. Ohshima H, Tatemichi M, Sawa T. Chemical basis of inflammation-induced carcinogenesis. Arch Biochem Biophys. 2003;417(1):3-11.

8. Balkwill F, Charles KA, Mantovani A. Smoldering and polarized inflammation in the initiation and promotion of malignant disease. Cancer Cell. 2005;7(3):211-7.

9. Karin M. Nuclear factor-kappaB in cancer development and progression. Nature. 2006;441(7092):431-6.

10. Lin WW, Karin M. A cytokine-mediated link between innate immunity, inflammation, and cancer. J Clin Invest. 2007;117(5):1175-83.

11. Michaud DS. Chronic inflammation and bladder cancer. Urol Oncol. 2007;25(3):260-8.

12. Saito K, Kihara K. C-reactive protein as a biomarker for urological cancers. Nat Rev Urol. 2011;8(12):659-66.

13. Stein B, Schrader AJ, Wegener G, Seidel C, Kuczyk MA, Steffens S. Preoperative serum $C$ - reactive protein: a prognostic marker in patients with upper urinary tract urothelial carcinoma. BMC Cancer. 2013;13:101.

14. Hilmy M, Bartlett JM, Underwood MA, McMillan DC. The relationship between the systemic inflammatory response and survival in patients with transitional cell carcinoma of the urinary bladder. $\mathrm{Br} \mathrm{J}$ Cancer. 2005;92(4):625-7.
15. Kastelein RA, Hunter CA, Cua DJ. Discovery and biology of IL-23 and IL-27: related but functionally distinct regulators of inflammation. Annu Rev Immunol. 2007;25:221-42.

16. Hunter CA, Kastelein R. Interleukin-27: balancing protective and pathological immunity. Immunity. 2012;37(6):960-9.

17. Pflanz S, Timans JC, Cheung J, Rosales R, Kanzler H, Gilbert J, et al. IL-27, a heterodimeric cytokine composed of EBI3 and p28 protein, induces proliferation of naive CD4(+) T cells. Immunity. 2002;16(6):779-90.

18. Wojno ED, Hunter CA. New directions in the basic and translational biology of interleukin-27. Trends Immunol. 2012;33(2):91-7.

19. Stumhofer JS, Hunter CA. Advances in understanding the anti-inflammatory properties of IL-27. Immunol Lett. 2008;117(2):123-30.

20. Awasthi A, Carrier Y, Peron JP, Bettelli E, Kamanaka M, Flavell RA, et al. A dominant function for interleukin 27 in generating interleukin 10-producing anti-inflammatory T cells. Nat Immunol. 2007;8(12):1380-9.

21. Murugaiyan G, Saha B. IL-27 in tumor immunity and immunotherapy. Trends Mol Med. 2013;19(2):108-16.

22. Swarbrick A, Junankar SR, Batten M. Could the properties of IL-27 make it an ideal adjuvant for anticancer immunotherapy? Oncoimmunology. 2013;2(8):e25409.

23. Xu M, Mizoguchi I, Morishima N, Chiba Y, Mizuguchi J, Yoshimoto T: Regulation of antitumor immune responses by the IL-12 family cytokines, IL-12, IL-23, and IL-27. Clin Dev Immunol 2010, 2010.

24. Hisada M, Kamiya S, Fujita K, Belladonna ML, Aoki T, Koyanagi Y, et al. Potent antitumor activity of interleukin-27. Cancer Res. 2004;64(3):1152-6.

25. Shimizu M, Shimamura M, Owaki T, Asakawa M, Fujita K, Kudo M, et al. Antiangiogenic and antitumor activities of IL-27. J Immunol. 2006;176(12):7317-24.

26. Huang N, Liu L, Wang XZ, Liu D, Yin SY, Yang XD. Association of interleukin (IL)-12 and IL-27 gene polymorphisms with chronic obstructive pulmonary disease in a Chinese population. DNA Cell Biol. 2008;27(9):527-31.

27. Chae SC, Li CS, Kim KM, Yang JY, Zhang Q, Lee YC, et al. Identification of polymorphisms in human interleukin-27 and their association with asthma in a Korean population. J Hum Genet. 2007;52(4):355-61.

28. Li CS, Zhang Q, Lee KJ, Cho SW, Lee KM, Hahm KB, et al. Interleukin-27 polymorphisms are associated with inflammatory bowel diseases in a Korean population. J Gastroenterol Hepatol. 2009;24(10):1692-6.

29. Huang ZQ, Wang JL, Pan GG, Wei YS. Association of single nucleotide polymorphisms in IL-12 and IL-27 genes with colorectal cancer risk. Clin Biochem. 2012;45(1-2):54-9.

30. Tao YP, Wang WL, Li SY, Zhang J, Shi QZ, Zhao F, et al. Associations between polymorphisms in IL-12A, IL-12B, IL-12Rbeta1, IL-27 gene and serum levels of IL-12p40, IL-27p28 with esophageal cancer. J Cancer Res Clin Oncol. 2012;138(11):1891-900.

31. Zhao B, Meng LQ, Huang HN, Pan Y, Xu QQ. A novel functional polymorphism, $16974 \mathrm{~A} / \mathrm{C}$, in the interleukin-12-3' untranslated region is associated with risk of glioma. DNA Cell Biol. 2009;28(7):335-41.

32. Hu T, Zhao H, Wang K, Sun W, Li L, Wang W: Association of IL-27 polymorphisms and cancer risk in Chinese population. J Recept Signal Transduct Res 2015;35(2):180-3.

33. $X u$ XP, Hua LY, Chao HL, Chen ZX, Wang XF, Ji J, et al. Genetic association between IL-27 rs153109 polymorphism and cancer risk in Chinese population: a meta-analysis. J Recept Signal Transduct Res 2014:1-6.

34. Ke X, Collins A, Ye S. PIRA PCR designer for restriction analysis of single nucleotide polymorphisms. Bioinformatics. 2001;17(9):838-9.

35. Sole X, Guino E, Valls J, Iniesta R, Moreno V. SNPStats: a web tool for the analysis of association studies. Bioinformatics. 2006;22(15):1928-9.

36. Devergne $\mathrm{O}$, Hummel M, Koeppen $\mathrm{H}$, Le Beau MM, Nathanson EC, Kieff E, et al. A novel interleukin-12 p40-related protein induced by latent Epstein-Barr virus infection in B lymphocytes. J Virol. 1996;70(2):1143-53.

37. Hall AO, Silver JS, Hunter CA. The immunobiology of IL-27. Adv Immunol. 2012;115:1-44.

38. Salcedo R, Stauffer JK, Lincoln E, Back TC, Hixon JA, Hahn C, et al. IL-27 mediates complete regression of orthotopic primary and metastatic murine neuroblastoma tumors: role for CD8+ T cells. J Immunol. 2004;173(12):7170-82.

39. Zhao H, Zhang Y, Xue F, Xu J, Fang Z. Interleukin-27 rs153109 polymorphism and the risk for immune thrombocytopenia. Autoimmunity. 2013;46(8):509-12.

40. Wei YS, Lan Y, Luo B, Lu D, Nong HB. Association of variants in the interleukin-27 and interleukin-12 gene with nasopharyngeal carcinoma. Mol Carcinog. 2009;48(8):751-7.

41. Zhang Z, Zhou B, Wu Y, Gao Q, Zhang K, Song Y, et al. Prognostic value of IL-27 polymorphisms and the susceptibility to epithelial ovarian cancer in a Chinese population. Immunogenetics. 2014;66(2):85-92. 
42. Santos AS, Melo ME, Crisostomo LG, Fukui RT, Matioli SR, Silva ME. Lack of association between IL27 gene variants and type 1 diabetes susceptibility. Cytokine. 2013;61(2):349-52.

43. Miyagaki T, Sugaya M, Shibata S, Ohmatsu H, Fujita H, Tamaki K. Serum interleukin-27 levels in patients with cutaneous T-cell lymphoma. Clin Exp Dermatol. 2010;35(4):e143-144.

44. Li HY, Zhang DL, Ge J, Zhou H, Qi A, Ma L, et al. Elevated interleukin-27 enhances the polarization of Th1/Tc1 cells and the production of proinflammatory cytokines in primary immune thrombocytopenia. Hum Immunol. 2012;73(3):240-7.

45. Diakowska D, Lewandowski A, Markocka-Maczka K, Grabowski K. Concentration of serum interleukin-27 increase in patients with lymph node metastatic gastroesophageal cancer. Adv Clin Exp Med. 2013;22(5):683-91.

46. Zolochevska O, Ellis J, Parelkar S, Chan-Seng D, Emrick T, Wei J, et al. Interleukin-27 gene delivery for modifying malignant interactions between prostate tumor and bone. Hum Gene Ther. 2013;24(12):970-81.

\section{Submit your next manuscript to BioMed Central and take full advantage of:}

- Convenient online submission

- Thorough peer review

- No space constraints or color figure charges

- Immediate publication on acceptance

- Inclusion in PubMed, CAS, Scopus and Google Scholar

- Research which is freely available for redistribution 